\title{
Behavioral variability and consistency: Experimental bases for a psychological theory of personality
}

\section{Variabilidad y Consistencia individual: Bases experimentales de la teoría de la personalidad}

\author{
José Santacreu Mas \\ Universidad Autónoma de Madrid, España \\ Disponible online 30 de abril de 2013
}

\begin{abstract}
The aim of this paper is to explain how and why individual differences emerge despite accounting for biological and socio-cultural differences, why people behave differently in the same context, and how behavior becomes stable and consistent. We review the experimental work on variability and stereotypy. In animal research, in contrast to expectations, there is interindividual variability in behavior under extreme environmental control. In addition, intraindividual consistency (stereotypy) is detected in animals whose behavior is not fully adjusted to the contingencies. The differences in what is learned (the kind of contingency relations) among laboratory animals can be explained by: a) the differences between effective contingencies and programmed contingencies, and b) the relationship between exploration and rate of reinforcement. In experimental studies in humans, learning differences in identical environments depend, further to the above, on what was previously learned by the individual (experience and education) and the thoroughness and internal consistency of task instructions. From these concepts, we propose a psychological theory of personality that explains: (a) how we learn different relationships from the same experience; (b) how behavioral individual differences emerge (variability); and (c) why each individual's behavior becomes stable and consistent.
\end{abstract}

Key words: Effective Contingencies; Programmed Contingencies; Exploration; Consistency; Variability; Individual Differences; Personality.

El objetivo de este trabajo es explicar por qué hay diferencias individuales aun descartando las diferencias biológicas y las diferencias socioculturales. Concretamente, contestar por qué cada una de las personas se comporta de manera distinta en un mismo contexto y cómo esa manera idiosincrásica de comportarse llega ser estable y consistente. Para ello se revisan los trabajos experimentales con animales sobre variabilidad y estereotipia en los que, en contra de lo esperado, se produce variabilidad en el comportamiento interindividual en condiciones extremas de control ambiental al mismo tiempo que se detecta consistencia intraindividual (estereotipia) en los animales cuyo comportamiento no se ajusta totalmente a lo que establecen las contingencias. Las diferencias respecto a qué se aprende en un contexto específico (qué relaciones de contingencia) entre los animales de laboratorio se explican por a) las diferencias entre las contingencias efectivas y las contingencias programadas y b) la relación entre exploración y tasa de reforzamiento. En los estudios experimentales en humanos, las diferencias de aprendizaje en contextos idénticos dependen, además de lo anteriormente señalado, de lo previamente aprendido por el individuo (experiencia e instrucción) y de la coherencia y completitud de las instrucciones de la tarea. A partir de estos conceptos se propone una teoría psicológica de la personalidad que explica: a) cómo se aprenden relaciones diferentes de una misma experiencia; b) cómo emergen las diferencias individuales del comportamiento (variabilidad) y c) por qué llega a ser estable y consistente el comportamiento idiosincrásico de cada individuo.

Palabras clave: Contingencias Efectivas; Contingencias Programadas; Exploración; Consistencia; Variabilidad; Diferencias Individuales; Personalidad.

Esta investigación ha sido parcialmente financiada por el proyecto de investigación MINECO PSI2011-27000

Correspondence concerning this article should be addressed to: Prof. Dr. José Santacreu Mas. Universidad Autónoma de Madrid. Psychology Faculty. Iván Pavlov, 6. 28049 Madrid (Spain). E-mail: $\underline{\text { Jose.santacreu@uam.es. }}$ 
Behavioral differences: individual and contextual variables

Very little can be added to Cronbach's $(1957,1975)$ analyses regarding the two disciplines of scientific Psychology (experimental vs. correlational psychology). Despite numerous attempts to integrate research, essentially, the situation has not varied. Currently, discussion focuses on establishing a conceptual and theoretical framework that would allow us manage the research data in both fields of the psychology and thereby take advantage of the knowledge generated in psychological research, integrating it without violating the assumptions of one of the two positions each time. With the aim of contributing to this theoretical and conceptual framework we aim to study behavioral differences as a function both of the variables that characterize the individual and the variables that shape the context.

Personality was initially considered a characteristic of the individual assessed at a certain moment, which corresponds to the synthesis of the individual's history; his/her ontogenetic development up to that moment (Santacreu, 2005). Personality is shown through idiosyncratic and consistent behavior in an individual in a set of similar situations. The behavior must be consistent both from an intraindividual and an intersituational perspective.

It is important to take into account that, as with behavior involving aptitudes, personality-related behavior must be assessed in well controlled assessment contexts. Assessment in natural contexts may be contaminated during the process due to learning or motivational variables.

In this work, various crucial questions about the theory of personality are presented, which can be summed up as follows: In the same situation, why does each person behave differently, and why does this idiosyncratic behavior become consistent and stable? Obviously the answer "individuals behave differently in the same situation because they have different personalities" is a tautological answer. In the same respect, to say "people behave stable and consistent because they have personality" is not an explanation of the data. To answer this question, we analyze the basic research on variability (interindividual differences) and stereotypy (intraindividual consistency and stability) that emerges in controlled experiments with animals in the field of learning.

The basic idea is that, within a context (understood as a well-defined task), everyone could be expected to potentially behave in the same way, achieving the same goals. If, however, this is not the case, it is no doubt due to the fact that every person, in their own experience in that context, has learned something different. However, this statement contradicts the notion from Psychology of Learning that, in identical contexts, everyone learns the same thing, if enough time is given. At least in the laboratory, all individuals learn according to the contingencies specified (programmed) in the context. One could only justify people learning different things in the same context if each one of them was already different (biology, knowledge, experience, motivation) from the start. In this case, in effect, one would admit that, even in the same learning context, individuals learn different relations.

It must be taken into account that any new learning experience affects individuals as a function of their prior experience, of what they have already learned, even in that same context. Thus, Staddon and Cerutti (2003) argued that the individual who is exposed for a second time to the same situation is no longer the same one who was exposed the first time. Individuals change with each trial and this change is irreversible. This argument implies that individuals' process of development produces an increasingly larger differentiation among them because the new experiences, even if they are strictly the same, have a different effect on each one of them (Witkin, 1974).

The current predominant proposal in psychology states that initial differences among individuals are due to genetic and epigenetic differences that are expressed in their biological development, and this is therefore the essential explanation of behavioral differences between individuals (Pervin \& John, 2008; Svrakic \& Cloninger, 2010).

From this moment on, our interest is to avert explanations based on initial differences among individuals. No doubt, initial differences explain an important part of the variance of behavior, but now, we shall focus on why even initially identical individuals end up behaving differently in the same context.

In summary, we have to explain how in new and controlled contexts, individuals ab initio considered identical, generate different behaviors. We propose that the explanation of the behavior variability of experimental individuals in laboratory, could contribute to the personality theory if, indeed, we can explain why subjects show variability in one learning context, and why some of them show stability and stereotyping in that context.

\section{Variability in studies with laboratory animals}

In experimental studies with animals, investigators have wondered how, in controlled environments such as a Skinner box, animals from the same strain, with the same experience, behave differently than expected as a function of the programmed contingencies.

Animals in laboratory studies usually behave similarly in each experimental condition according to the programmed contingencies. Nevertheless, there is some variability in their behavior, which does not prevent the establishment of general laws of behavior. This interindividual variability used to be considered noise, the result of insufficient experimental control. However, this phenomenon has recently been systematically analyzed by many laboratories (Neuringer, 2002)

Intersubject behavioral variability is thought to emerge as a result of the programmed contingencies in a certain context without any need for direct reinforcement. In this regard, many authors have attempted to clarify the kind of contexts in which 
this variability emerges and they have investigated the variables that it could depend on. It has been known for some time that continuous reinforcement programs induce little variability, whereas extinction programs favor interindividual variability (Kinloch, Foster \& McEwan 2009). Greater reinforcement delay when acquiring the response also produces greater variability (Odum, Ward, Burke \& Barnes, 2006). Other authors have established that intermittent reinforcement schedules, especially variable interval schedules, generally induce variability in a larger number of individuals. Moreover, some authors propose that behavioral variability can be induced by controlling the contextual contingencies (Mechner, Hyten, Field \& Madden, 1997; Wagner \& Neuringer, 2006). Inducing variability, defining previously what is exactly a variation in behavior, and controlling these variations by means of contextual contingencies is a novel approach in the study of variability. Variability can be induced if we reinforce a sequence of $n$ responses (R1, $\mathrm{R} 2, \mathrm{R} 1, \mathrm{R} 1)$ whose execution sequence is different from the sequence that was reinforced in the previous trial (R1, R1, R2, $\mathrm{R} 1)$. This is an alternative proposition to the previous hypothesis that states that the reinforcement program induces variability in some subjects. In this regard, the variability in animal experiments may be due to both contextual variables and the individual-context interaction.

Moreno and Hunziker (2008) carried out a clarifying conceptual analysis of the term variability without which it is difficult to integrate all the research on the topic. These authors state that the way in which variability emerges among individuals in a new and identical context must be explained separately from how it remains stable in each individual once the different pattern of behavior has been established. For this purpose, the definition of the term behavioral variability is crucial. To assess the degree of variability, on the one hand, the response characteristics must be defined, specifying its parameters (magnitude, frequency, duration, etc.) and the criteria to which we refer when attempting to determine differences, establishing the type of distribution we expect.

Our goal is not to show how we can induce variability (exploration or creativity, as noted by Neuringer (2002, 2004), but to account for how the program of contingencies specified in a new context generates stable patterns of behavior in some individuals, which match the programmed contingencies of the context (they learn), whereas in other individuals, different behavioral patterns are produced, which, although they do not completely match the context contingencies, are stable and idiosyncratic and achieve a certain rate of reinforcement.

To deal with the explanation of individuals' behavioral variability in novel controlled contexts, where the behavior is necessarily a function of the contingencies, we initially accept the following assumptions, which we will attempt to illustrate through a simulated experiment in a Skinner box, in which we programmed the contingencies specified in Figure 1:
Figure 1

Outline of the contingencies that operate in an experimental box with two retractile bars (right $\mathrm{RB}$ and left LB) and a green light (GL) that switches on or off in a 10-s cycle if there are no responses. In the fourth column, the type of learning that is operating is specified.

\begin{tabular}{|c|c|c|c|}
\hline $\begin{array}{c}\text { Antecedent } \\
\text { stimulus }\end{array}$ & Response & Consequence & Learning \\
\hline \multirow[b]{3}{*}{$\mathrm{E}^{\mathrm{d}}$ Green light on } & \multirow{3}{*}{$\begin{array}{l}\text { RB } \\
\text { Right bar }\end{array}$} & 1 food pellet & $\begin{array}{l}\text { Positive } \\
\text { reinforcement }\end{array}$ \\
\hline & & $\begin{array}{l}\text { The bars are } \\
\text { retracted (5 s) }\end{array}$ & $\begin{array}{c}\text { Negative } \\
\text { punishment }\end{array}$ \\
\hline & & $\begin{array}{c}\text { GL switches off } \\
(\mathbf{1 0} \mathbf{s}) \\
\text { The light-off }(10 \mathrm{~s}) / \\
\text { light-on }(10 \mathrm{~s}) \text { cycle } \\
\text { restarts }\end{array}$ & $\begin{array}{l}\text { Negative } \\
\text { punishment }\end{array}$ \\
\hline $\mathrm{E}^{\mathrm{d}}$ Green light on & $\begin{array}{l}\text { LB } \\
\text { Left bar }\end{array}$ & $\begin{array}{c}\text { None } \\
\text { No changes }\end{array}$ & $\begin{array}{l}\text { Only response } \\
\text { cost for pressing }\end{array}$ \\
\hline $\mathrm{E}^{\Delta}$ Green light off & $\begin{array}{l}\text { RB } \\
\text { Right bar }\end{array}$ & $\begin{array}{l}\text { The bars are } \\
\text { retracted }(5 \text { s) } \\
\text { Does not affect the } \\
\text { on /off cycle of GL. }\end{array}$ & $\begin{array}{l}\text { Negative } \\
\text { punishment }\end{array}$ \\
\hline $\mathrm{E}^{\Delta}$ Green light off & $\begin{array}{l}\text { LB } \\
\text { Left bar }\end{array}$ & $\begin{array}{c}\text { None } \\
\text { No changes }\end{array}$ & $\begin{array}{l}\text { Only response } \\
\text { cost for pressing }\end{array}$ \\
\hline
\end{tabular}

1. An individual's history is the history of the series of his/her interactions, and each new interaction within a context, is a function of his former history of interactions within that context. As noted by Staddon and Cerutti (2003), an individual's behavior can be reversed but not the state of his organism (his history).

Experimental box: Each new choice of the rat in the Skinner box is a function of the set of prior choices. Thus, if at a certain moment, the rat pressed the right bar (RB) several times and this was reinforced, it will very probably press $\mathrm{RB}$, but if it has not received reinforcement at $\mathrm{RB}$ because it did not press it when the green light (GL) was switched on, then it is equally likely to press either one of the two bars, exploring possible solutions.

2. If the context has a finite number of specified contingencies and these are stable, each individual will modify his/her behavior, adapting it to the contingencies and learning. The last column of Figure 1 describes the learning processes that could be operating in the experiment we designed.

Experimental box: For the former example, each individual will learn and ultimately press RB only when the GL is switched on.

3. Although the contingencies do not change within a context, and the programmed contingencies are identical for all the subjects, the learning histories of each individual cannot always be matched.

Experimental box: In this experiment, all the animals ultimately press the RB, some only do it if the GL is on, and others will not stop pressing the left bar (LB) even though it is not reinforced.

4. In a context in which there are unique and precisely programmed contingencies, at a certain moment, as a consequence of the interaction, one subject may learn "effective" contingencies that are different from those programmed by 
the experimenter. The set of relationships that an individual learns in a context are called "effective contingencies". Such effective contingencies explain their behavior and have varying degrees of adjustment to scheduled contingencies in an experiment as well as to the actual contingencies in a natural context.

Experimental box: When the bars appear, an animal might first press the LB (nothing happens), and then, when the GL lights up, it presses the RB, the bar that is reinforced. Thus, it obtains a similar rate of reinforcement to that of another subject that waits and presses RB only when the GL is on. The contingency relation that operates in the first case could be "reinforcement is obtained by pressing LB and then, when the GL lights up, by pressing RB," in contrast to the second case, whose relation would be "reinforcement is obtained by pressing the RB when the GL is on".

5. As a consequence of the interaction, equally programmed contexts for all individuals are different for each person with regard to the temporal characteristics of the stimuli.

Experimental box: In our simulated experiment, when pressing RB (the correct one) both bars are 5 seconds retracted, even when the GL is out. Thus, depending on the moment when the subject presses (at the beginning or at the end of the 10-second no-GL interval), the bars may not be available when the GL is on.

To sum up, according to these assumptions, although most individuals finally adapt to the contingencies established in a situation, both in people's real life and in the laboratory, we cannot affirm that all the subjects learn the contingency relations established (programmed) in the context. In general, individuals adapt to the context, they learn, achieving the desired consequences, but not all of them learn exactly the same relationship. A molecular analysis of their behavior (of the sequences of actions between reinforcements) suggests that they learn contingencies that are effective inasmuch as they achieve a "reasonable rate of reinforcement" but they do not always learn the strict contingency relations established or programmed in the situation.

Using humans as participants, Lozano, Hernandez \& Santacreu (2011) have shown the extensive variability of interindividual behavior in a simple choice task (the Flag Test, see Lozano et al., 2011) on a RF3 operant conditioning schedule. In this task, participants were asked to click on different flags on the computer screen for reinforcement. The scheduled contingency was to click three times on a specific flag (the Brazilian one) out of ten. At the end of the trials, only a few people clicked three times on the correct flag (total adjustment to the contingencies set). There were a large number of participants who received the reinforcement pressing an idiosyncratic sequence, systematically repeated, which necessarily included the triple click on the correct answer, but also other different flags. All of them thought they had learnt since they had received an immediate reinforcement by pressing their sequence (e.g., pressing a sequence of 5 flags: flag 8, flag 1, flag 8, flag 1 flag 8). But each of them had learnt a different sequence, in line with effective contingencies. Their behavior was consistent (stereotypy) but different from other individuals (variability). More than half of the participants in this study clicked more than 3 flags after 20 training trials.

Figure 2 shows the record of two people in this task. One of them belongs to the group that learned before the 10 trials, whereas the other did not manage to learn the programmed contingencies but did stabilize their behavior pattern. The person who learned reached the learning criterion and continued in the asymptote. The one who did not learn began the asymptote at Trial 8 and maintained it practically stable until Trial 20, without improving his level of learning.

In summary, from a psychological perspective, differentiation in the development and variability of individual behavior, can produce different response patterns (different learning) in initially identical individuals. This is because the experience in one context may be different for each individual based on the successive interactions in this context. Consequently, some individuals learn contingency relationships (effective contingencies) relatively different from contingencies programmed so that, if they reach a certain rate of reinforcement, they did not explore other alternatives more effective or efficient and, consequently, each individual repeated one different response pattern that achieves certain degree of reinforcement.

\section{Figure 2}

Learning curves of two adult university graduates in the Flags test. Both of them stabilize their response pattern at Trial 10 but with a different level of learning.

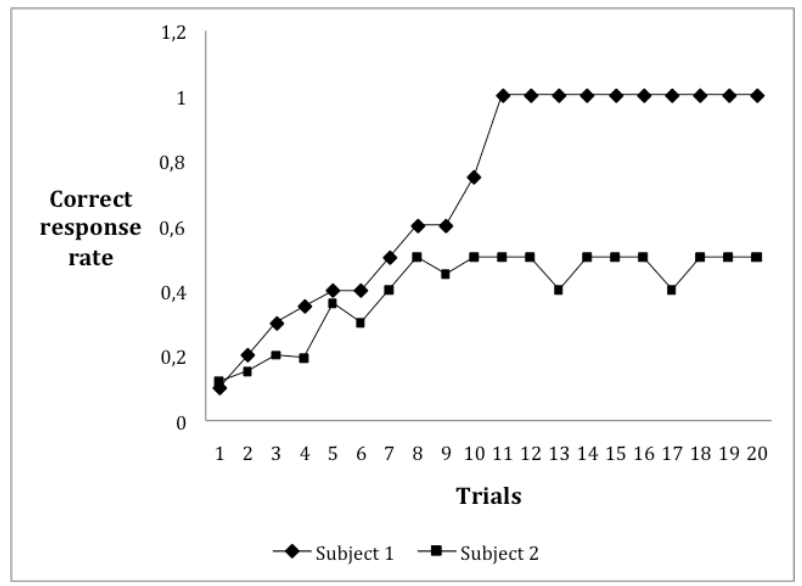

\section{Stereotypy or the intraindividual consistency of idiosyn- cratic behavior}

Even though they have not learned the strictly programmed contingency relation, individuals who maintain a systematic response pattern in each trial obtain a reasonable rate of reinforcement. This group of individuals does not behave with maximum 
efficacy (performing only the necessary and sufficient behavior to obtain reinforcement) or efficiency (performing the behavior that obtains reinforcement with the least cost, least time, or with shorter response sequences) but they do achieve some rate of reinforcement. The rate of reinforcement of the two participants in Figure 2 is very similar: the individual who learns gets 6 reinforcements per minute (just click the target flag 3 times), and the participant who does not learn but has a stable response pattern gets 5 reinforcements per minute (click 3 times the target flag and click two other non-target flags) Now, the question is: Why do some individuals stabilize their behavior (they repeat behavior patterns) with lower reinforcement rates than the maximum rate afforded by the context?

We propose three key concepts to explain why, in the same context, each individual learns different relations from the expected ones and, nevertheless, they are stable and consistent. The first one refers to the degree of information from the context, i.e., the way the task is presented and how the individual is shown what the task consists of and how to solve it; the second refers to the degree of exploration-association that is characteristic of each individual; and the third refers to the incentive differential in each trial as a function of whether the individual responds as in the previous trial or changes his response pattern to achieve a better result (see Figure 3 for a summary of the arguments involved in the questions posed).

Figure 3

Outline of assumptions, questions and answers about learning and intraindividual consistency, exploration-association, variability-stereotypy and the differential incentive.

\begin{tabular}{|c|c|}
\hline \multicolumn{2}{|l|}{ ASSUMPTIONS of LEARNING } \\
\hline \multicolumn{2}{|c|}{$\begin{array}{l}\text { - In a new context, the individual performs the responses from his repertoire } \\
\text { until at some point, some of these responses are reinforced. }\end{array}$} \\
\hline \multirow{2}{*}{\multicolumn{2}{|c|}{$\begin{array}{l}\text { Exploration is adaptive and allows one individual to adapt to new contexts. } \\
\text { - The individual who learns repeats the pattern of responses that obtain the } \\
\text { maximum rate of reinforcement. }\end{array}$}} \\
\hline & \\
\hline \multirow{2}{*}{\multicolumn{2}{|c|}{$\begin{array}{l}\text { Individual differences, with regard to the asymptote of the learning level, } \\
\text { depend on the exploration gradient and the incentive differential, trial to trial. } \\
\text { - Even if it is not efficient, repeating (versus exploring) a behavioral pattern } \\
\text { that achieves some rate of reinforcement is adaptive as long as it is guaranteed } \\
\text { to obtain it. }\end{array}$}} \\
\hline & \\
\hline QUESTIONS & ANSWERS \\
\hline \multirow{2}{*}{$\begin{array}{l}\text { Why do individuals repeat } \\
\text { their behavioral patterns } \\
\text { (stereotypy) at the end of } \\
\text { the training, when they have } \\
\text { managed to learn? }\end{array}$} & $\begin{array}{l}\text { the } \\
\text { the }\end{array}$ \\
\hline & $\begin{array}{l}\text { sociating } \\
\text { nforced. }\end{array}$ \\
\hline \multirow[t]{2}{*}{$\begin{array}{l}\text { Why is the behavior repeated } \\
\text { (stereotypy) at the end of } \\
\text { training, even when the } \\
\text { individual has not managed } \\
\text { to learn? }\end{array}$} & $\begin{array}{l}\text { se or } \\
\text { stable } \\
\text { not be }\end{array}$ \\
\hline & \\
\hline \multirow{2}{*}{$\begin{array}{l}\text { In the same context, on } \\
\text { what does the degree of } \\
\text { exploration (variation of the } \\
\text { behavior) depend? }\end{array}$} & $\begin{array}{l}\text { 1. Exploration will incre } \\
\text { and/or }\end{array}$ \\
\hline & $\begin{array}{l}\text { 2. If repeating the behavior (the same behavior } \\
\text { that was previously reinforced) is not reinforced } \\
\text { or it is punished. }\end{array}$ \\
\hline $\begin{array}{l}\text { On what does a subject's } \\
\text { exploration } \\
\text { independently of the level of } \\
\text { learning achieved? }\end{array}$ & $\begin{array}{l}\text { The degree of exploration depends on the } \\
\text { incentive for exploring, that is, on the difference } \\
\text { between what the subject would gain by } \\
\text { repeating versus what he/she would gain by } \\
\text { exploring in a new trial. }\end{array}$ \\
\hline
\end{tabular}

We shall define these three concepts to clarify their function:

1. Degree of context information (accuracy and completeness) about the key response. The characteristics of the selected response, the variations of the antecedent stimuli, the disposition of the trials, the contingency changes that are not discriminated, the result reported for each response, the value of the response-consequence (R-C) contingency (Balsam, Deich, Ohyama, \& Stokes, 1998; Segal, 1972) or the precision of the task instructions in humans (Martínez, Ortiz, \& González, 2007) are characteristics of the context that provide information about which is the correct response and of what it consists. Let us analyze the degree of information of the variable "the result reported for each response". For example, to pass a certain test the participant must travel a circuit riding a bike adjusting his/her speed to $15 \mathrm{~km} / \mathrm{h}$. Information about speed can be reported by a speedometer installed in the vehicle or at the end of each trial. In the first case, the context accurately informs the response and, consequently, the speed variability is reduced in the test.

2. Exploration-association gradient is a concept referring to the individual's functioning in his attempt to adapt or adjust to the contextual contingencies. In a new context, the individual initially explores, performing different behaviors successively until he/she learns, that is, he/she associates a certain response pattern to the desired consequence. Afterwards, he/she repeats the response pattern with which they systematically achieve reinforcement, gradually reducing the degree of exploration. Exploration and association are two essential elements to explain the process of learning in a new context (Sutton \& Barto, 1998; Dam \& Körding, 2009). Our position is that individuals differ in the degree to which they associate and explore, taking into account that in the course of learning, interaction with a specific context modifies the values of both variables association and exploration idiosyncratically.

3. Incentive differential refers to the relation between the profit gained for performing a variant of the response pattern and the profit gained for performing the previous pattern. The incentive differential determines the balance of exploration-association or the balance of exploration-exploitation of previous knowledge, as it is called in the business world (Katila \& Ahuja, 2002; March, 1991).

Thus, as a consequence of the learning process throughout the trials, to the extent to which they learn (associate), individuals reduce exploration. Learning is reducing the variability of the set of possible responses, increasingly adapting to the established contingencies. This reduced exploration is seen in the stability of each individual's intraindividual response pattern, and this occurs no matter whether they have learned the strictly programmed contingencies or whether there is an important difference between these programmed contingencies and the 
effective contingencies, as long as a certain rate of reinforcement is attained. In the above-mentioned study (Lozano et al., 2011), individuals reduced the number of flags they pressed, concentrating on a few flags as the trials advanced.

Neuringer notes that variability is related to exploration, but he suggests that exploration is not related to the difficulty to adjust to the programmed contingencies but instead to the fact that a response or a response pattern has been potentially reinforced in the course of the learning process. This author has shown that it is possible to increase the variations by reinforcing responses that are different from the previously performed responses and that "Creativity, exploration, and problem solving may depend partly on operant variability" (Neuringer, 2002, p. 672).

However, our position is different. The question is: on what does response pattern stability depend, when the individual does not completely adjust to the programmed contingencies by the end of the training, and, therefore, does not achieve the maximum rate of reinforcement? Our proposal is that the degree of exploration in a new context, at the beginning of training, depends on the degree of motivation in each trial. The higher the degree of motivation, the higher the degree of initial exploration and variability of the responses. However, at the end of training, the degree of exploration in each trial depends on the rate of reinforcement and, consequently, its reduction is the result of the decrease of motivation due to the consumption of the reinforcement.

From the investigator's perspective, stability and consistency in the response pattern (stereotypy in animal research) is only reasonable when learning is complete and the maximum reinforcement rate has been achieved. However, the participant in the experiment may not know whether he has reached the learning criterion or whether or not he is performing the correct behavior. We shall now analyze the subject's behavior in each action. Our hypothesis is that individuals will behave adjusting the incentive differential between exploiting what they have learned (repeating the response pattern that provided some reinforcement in the previous trial) and exploring new alternatives (variants of the response pattern of the previous trial) that could produce greater benefits. If, they perform the alternative response pattern and improve the benefits in a certain trial, they may try to consolidate this again. If not, they can always return to the previous alternative and attain the rate of reinforcement they were obtaining before. Some individuals are more prepared to continue exploring, whereas others conform to the rate of reinforcement they are achieving. Note that this reasoning gives a possible way for describing learning processes in order to explain behavioral variability of individuals. In fact, it has been considered in Sutton \& Barton's (1998) algorithms for simulating the operant conditioning process.

In short, with sufficient training most individuals stabilize their behavior, repeating the pattern that achieves its idiosyncratic reinforcement rate regardless of the reinforcement contingencies programmed by the experimenter. When the degree of adjustment to context contingencies is full, the experimenter said that the individual has learned and, naturally, their behavior is consistent. When, on the contrary, individuals have not fully learned programmed contingencies, the experimenter said that the behavior of subjects varies (there are interindividual differences in learning) although there may be stereotyping (intraindividual consistency) or systematic repetition of the response pattern in each trial.

\section{Implications for a personality theory}

The personality theory that we propose takes into account two main aspects. The first is that personality psychology, as a discipline of psychology, aims to study the individual's consistent behavior in certain types of context. In other words, the frequency or intensity of a consistent and stable behavior cannot be considered by itself an indicator of an individual's personality. The second is that the characteristics of these contexts allow us to study the nomenclature of the personality variables. Thus, the taxonomy of personality types is established as a function of the contexts and the individuals' interaction with these contexts. For example, only in a "context of risk", in which one can choose among options that vary in the probability of losses or benefits, we can assess the "risk accepted" by each individual. Taking this into account, personality psychology proposes to identify consistent behavioral tendencies in any sample of individuals in different types of situations that are adequate for assessment.

Now it is necessary to define the characteristics of the contexts that make them useful for the assessment of such trends. First, the situations or assessment tasks should not represent learning contexts in which the individual's behavior could be mediated by the contingencies operating in the task. Second, individuals should be naïve regarding these tasks. Assessment tasks must be different from natural situations in their morphology but not in terms of their functionality, in the same way an intelligence test item should not look like a problem of daily life. Finally, the context should not provide feedback to the individual's performance. In summary, to assess personality, it is necessary to design objective tests similar to those used in the evaluation of skills and competences (Cattell, 1979, 1980, 1983; Hernández, 2000).

With regard to the study of the consistency of behaviors related to capacities or aptitudes, the research data consolidate the conclusion that people are consistent in aptitude tests; in other words, in the things that they have learned in a precise and definite way throughout their ontogenetic development, totally adapting to the contingencies of natural contexts. We refer to what is known as adapting to the programmed contingencies in an experiment and, in a person's development, this would be learning to perceive, to estimate the distance of objects as a function of their size, to estimate speed, to add, etc. Whatever the individual may have learned will determine the degree of aptitude or competence currently possessed and can be assessed 
by means of a test. Whatever is completely learned within a context remains relatively stable in individuals, and they generalize and transfer this appropriately to functionally similar contexts. Under this assumption, psychologists usually assess spatial, motor, and verbal aptitudes or specific competences, such as riding a bicycle.

What do we mean when we refer to behavior styles or personality? We are referring to what the person has learned in contexts that provide scarce information about the correct behavior, in which there are few trials or occasions in which to learn, the context contingencies frequently change, or there is no clear and continuous feedback about the results. Surprisingly, as we noted in studies with animals, in these situations, individuals learn and perform consistent patterns of behavior. By means of the description in Figure 4, it is easier to understand what kind of situations we are referring to and how individuals learn contingencies that are at least effective, even if they do not correspond to the situation. Thus, we consider that personality refers to consistent behavior that has been learned in contexts that generate variability or individual differences. In daily life, a person often encounters these types of context (Hernández, Santacreu \& Rubio, 1999; Santacreu, 2005).

\section{Figure 4}

Example of a context with a low degree of information about the correct response and the change of contingencies. Individual differences (variability) will be generated, and some individuals learn effective relations that are different from the programmed ones.

\section{THE LIGHT SWITCHES ON WHEN I ENTER MY OFFICE.}

Let us imagine a context in which the following contingencies operate for an individual:

\section{Effective contingencies:}

"As soon as I enter my office, the light switches on. I always thought that the room recognized me as the occupant and owner of the office. I thought it was submission accepted by the office. One day, the light did not turn on and I had to scold the office severely, ordering it to switch on the light, and it did so. Now, I always have to demand it rudely, shouting, but it is still sometimes reluctant".

\section{Programmed contingencies :}

"Any little noise in the room that exceeds the preestablished threshold switches on the light"

\section{Change in contingencies:}

"When cleaning the heating pipes, someone inadvertently changed the sensitivity of the room's noise sensor that turns on the light and the air conditioner".

\section{EXPLANATION}

In these contexts, different stereotyped sequences are produced in each individual, and their only requirement is that they adapt to one of the possible contingencies described in the context. In the example, we could say that the subject's phrase "Switch on the light!" or "Here I am !" turns on the light, although the programmed contingency is "any n-decibel noise turns the light on".

In the contexts or tasks designed to assess personality (for example, risk, persistence, thoroughness, or cooperation), consistency values (intersituational or intraindividual) hardly reach values as high as those achieved to assess aptitudes and competences, because personality consistency values refer to behaviors in situations in which the changing context contingencies were not learned and it is therefore very difficult to generalize them to functionally similar contexts (for instance, in the same situation, sometimes creativity and spontaneity are reinforced, and sometimes thoroughness and persistence) (Rubio, Santacreu \& Hernández, 2004; Rubio, Hernández, Zaldívar, Márquez \& Santacreu, 2010).

In situations that produce great variability, we can study the idiosyncratic tendency of each individual but, from a scientific perspective, it only makes sense to study this behavioral tendency if each individual is consistent in the way he deals with the situation. Therefore, personality, which as noted by Funder (2009), can only have the empirical goal of predicting behavior in specific situations, will study the behavioral tendencies in which individuals differ from each other but in which the individuals themselves are consistent (Hernández, Santacreu, Revuelta \& Rubio, 2006; Rubio, Hernández, Revuelta \& Santacreu, 2011).

Summing up, the present work constitutes an alternative and feasible viewpoint for a psychological theory of personality inasmuch as it explains how individual differences are generated and, particularly, intraindividual consistency throughout the individual's history. The goal of the present work is to explain how consistent and stable behavioral styles become incorporated into each individual based on experimental studies with animals.

The personality theory outlined herein offers, in psychological terms, an explanation that does not invalidate, but instead complements, other explanations of personality of a genetic and biological-developmental nature. However, as a psychological theory, it must be supported by assessment through objective tests that allow us to assess the behavioral style in the appropriate contexts (Cattell, 1980; Santacreu, Rubio \& Hernández, 2006).

Strictly, our proposal is to develop a theory of the genesis of personality, which explains how it generates variability and individual consistency following the experience in certain contexts. It remains to explain how synthesis is generated from experience and as permanently incorporated into the individual's history. In addition, to contribute to a theory of personality, we also have to explain how the individual consolidates variability and consistency of behavior across development.

\section{References}

1. Balsam, P. D., Deich, J. D., Ohyama, T. \& Stokes, P. D. (1998). Origins of new behavior. In W. O’Donohue (Ed.), Learning and behavior therapy (pp. 403-420). Boston: Allyn \& Bacon.

2. Cattell, R. B. (1980). Personality and learning theory: Vol. 2. A systems theory of maturation and structured learning. New York: Springer.

3. Cronbach, L. J. (1957). The two disciplines of scientific psychology. American Psychologist, 12, 671-684. http:// dx.doi.org/10.1037/h0043943

4. Cronbach, L. J. (1975). Beyond the two disciplines of scientific psychology. American Psychologist, 30, 116-127. http://dx.doi.org/10.1037/h0076829

5. Dam, G. \& Körding, K. (2009). Exploration and exploita- 
tion during sequential search. Cognitive Science, 33, 530541. http://dx.doi.org/10.1111/j.1551-6709.2009.01021.x

6. Funder, D. C. (2009). Persons, behaviors and situations: An agenda for personality psychology in the postwar era. Journal of Research in Personality 43, 120-126. http://dx.doi. org/10.1016/j.jrp.2008.12.041

7. Hernández, J.M., Santacreu, J. \& Rubio, V. (1999). Evaluación de la personalidad: Una alternativa teórico metodológica [Personality assessment: A theoretical methodological alternative]. Escritos de Psicología, 3, 20-28.

8. Hernández, J.M., Rubio, V.J., Revuelta, J. \& Santacreu, J. (2006). A Procedure for Estimating Intrasubject Behavior Consistency. Educational and Psychological Measurement, 66, 417-434. http://dx.doi.org/10.1177/0013164405275667

9. Hernández, J. M., Santacreu J. Revuelta, J. \& Rubio, V. (2011). Are We more Consistent when Talking about Ourselves than when Behaving? Consistency Differences through a Questionnaire and an Objective Task. The Spanish Journal of Psychology, 14, 207-217. http://dx.doi.org/10.5209/rev SJOP.2011.v14.n1.18

10. Katila, R \& Ahuja, G. (2002). Something old, something new: a longitudinal study of search behavior and new product introduction. Academy of Management Journal, 45, 11831194. http://dx.doi.org/10.2307/3069433

11. Kinloch, J. M., Foster, T. M. \& McEwan, J. S. A. (2009). Extinction-induced variability in human behavior. The Psychological Record, 59, 347-370.

12. Lozano, J. H., Hernandez, J. M. \& Santacreu, J. (2011). Fluid intelligence and discriminative operant learning of reinforcement contingencies in a fixed-ratio 3 schedule. Learning and Individual Differences, 21, 585-589. http://dx.doi. org/10.1016/j.lindif.2011.07.009

13. March, J. G. (1991). Exploration and exploitation in organizational learning. Organization Science, 2, 71-87. http:// dx.doi.org/10.1287/orsc.2.1.71

14. Martínez, H., Ortiz, G. \& González, A. (2007). Efectos diferenciales de instrucciones y consecuencias en ejecuciones de discriminación condicional humana [Differential effects of instructions and consequences in performances of human conditional discrimination]. Psicothema, 19, 14-22.

15. Mechner, F., Hyten, C., Field, D. P. \& Madden, G. (1997). Using revealed operants to study the structure and properties of human operant behavior. Psychological Record, 47, 45-68.

16. Moreno R., \& Hunziker, M. H. L. (2008). Behavioral variability: A unified notion and some criteria for experimental analysis. Mexican Journal of Behavior Analysis, 34, 133-143.

17. Neuringer, A. (2002). Operant variability: Evidence, functions, and theory. Psychonomic Bulletin \& Review, 9, 672705. http://dx.doi.org/10.3758/BF03196324

18. Neuringer, A. (2004). Reinforced variability in animals and people: Implications for adaptative behavior. American Psychologist, 59, 891-906. http://dx.doi.org/10.1037/0003$\underline{066 X .59 .9 .891}$
19. Odum, A. L., Ward, R. D., Burke, K. \& Barnes, C. A. (2006). The effects of delayed reinforcement on variability and repetition of response sequences. Experimental Analysis of Behavior, 86, 159-179. http://dx.doi.org/10.1901/jeab.2006.58$\underline{05}$

20. Pervin, L. A. \& John, P.A. (2008). Personality: Theory and research London Guilford Press.

21. Pervin, L.A. (2003). The science of personality. ( $2^{\text {nd }}$ ed.) New York: Oxford University Press.

22. Rubio, V. J., Hernández, J. M. Revuelta, J. \& Santacreu, J (2011). Are we more consistent when talking about ourselves than when behaving? Consistency differences through a questionnaire and an objective task. The Spanish Journal of Psychology, 14, 207-217. http://dx.doi.org/10.5209/rev SJOP.2011.v14.n1.18

23. Rubio, V. J., Hernández, J. M., Zaldívar, F., Márquez, M. O. $\&$ Santacreu, J. (2010). Can we predict risk-taking behavior? Two tasks for predicting guessing tendencies in a multiple option test. European Journal of Psychological Assessment, 26, 87-94. http://dx.doi.org/10.1027/1015-5759/a000013

24. Rubio, V. J., Santacreu, J. \& Hernández, J. M. (2004). The objective assessment of personality. An alternative to selfreport based assessment. Análisis \& Modificación de Conducta, 30, 827-840.

25. Santacreu, J. (2005). La síntesis de la historia de aprendizaje: Perspectiva conductual sobre la personalidad [The synthesis of learning history: Behavioral perspective of personality]. Acta comportamentalia, 13, 53-56.

26. Santacreu, J., Rubio, V. J. \& Hernández, J. M. (2006). The objective assessment of personality: Cattells's T-Data revised and more. Psychology Science, 48, 53-68.

27. Segal, E. F. (1972). Induction and the provenance of operants. In R. M. Gilbert \& J. R. Millenson (Eds.), Reinforcement: Behavioral analyses (pp. 1-34). New York: Academic Press.

28. Svrakic, D.M. \&. Cloninger R.C. (2010). Epigenetic perspective on behavior development, personality, and personality disorders Psychiatria Danubina, 22, 153-166.

29. Staddon, J. E. R. \& Cerutti, D. T. (2003). Operant conditioning. Annual Review of Psychology, 54, 115-44. http://dx.doi. org/10.1146/annurev.psych.54.101601.145124

30. Sutton, R. S. \& Barto A. G. (1998). Reinforcement learning: An introduction. Cambridge, MA: MIT Press.

31. Wagner, K. \& Neuringer, A. (2006). Operant variability when reinforcement is delayed. Learning \& Behavior, 24, 111-123. http://dx.doi.org/10.3758/BF03193187

32. Witkin, H.A. (1974). Psychological differentiation: Studies of development (2nd ed.) New York: Wiley.

Received 30 September 2012 Received in revised form 5 February 2013 Accepted 8 February 2013 